\title{
A framework for software requirement ambiguity avoidance
}

\author{
Ashok Kumar Gupta ${ }^{1}$, Aziz Deraman ${ }^{2}$ \\ ${ }^{1}$ Department of Computer Science, Jazan University, KSA, Saudi Arabia \\ ${ }^{1,2}$ Universiti Malaysia Terengganu, Malaysia
}

\begin{tabular}{l}
\hline \hline Article Info \\
\hline Article history: \\
Received Jan 12, 2019 \\
Revised Apr 25, 2019 \\
Accepted Jun 14, 2019
\end{tabular}

Keywords:

Ambiguity

Elicitation technique selection

Requirement elicitation

Unambiguous requirements

\begin{abstract}
This research deals with software requirements ambiguity problems. Among these are incomplete, incorrect, improper, inaccurate and unambiguous requirements. Interestingly, published material related to Software Requirements Specifications (SRS) problems discusses ambiguity as one of the most conversed problems. This paper proposes a Software Requirement Ambiguity Avoidance Framework (SRAAF) to assist and support requirement engineers to write unambiguous requirements, by selecting correct elicitation technique based on the evaluation of various attributes and by applying the $\mathrm{W} 6 \mathrm{H}$ technique. We explored existing theories and the outcomes of experimental research to construct the framework. On the basis of existing and inferred knowledge, we tried to justify proposed frameworks components. Our selection process focuses on various situational attributes. We added various situational attributes related to project, stakeholders and requirement engineer for the selection process. Newly devised approach chooses techniques other than traditional techniques or most common techniques and deals with ambiguity to capture the correct requirements information from stakeholders. The framework will be able to address the selection and ambiguity issues in a more effective way and can handle vagueness. New evidence related to attributes and adequacy matrix can be easily added to the framework without any inconvenience.
\end{abstract}

Copyright @ 2019 Institute of Advanced Engineering and Science. All rights reserved.

\section{Corresponding Author:}

Ashok Gupta,

Department of Computer Science,

College of Computer Science and Information Technology,

Jazan University,

Jazan, Saudi Arabia.

Email: kgupta.ashok@gmail.com

\section{INTRODUCTION}

For software projects, Requirements Elicitation (RE) is crucial. As we know that in the later stages of the software, correcting errors becomes a very tedious job as errors escalate exponentially. Therefore, during the elicitation process, if we can identify these incorrect and ambiguous requirements that can decrease the cost of correcting these errors in the software significantly. Digging out Requirements is not easy as they are deep in the social and organizational structure of organizations. There exist a variety of elicitation techniques, each and every technique has its own pros and cons. There is no single technique, which can be effectively used for all type of problems.

Most of the time root cause of failures of software development projects are the poor quality SRS [1-3]. As per [4] the commonly used method of the software quality measurement is the empirical method, and few researchers adopted an AHP and Fuzzy technique in determining the software quality. There are many challenges associated, that it must be clear, correct, consistent, unambiguous, modifiable, verifiable and traceable, with a good quality SRS. Ambiguity is one of the major problems in the requirements specification. Ambiguity rarely surfaces during the development of a requirements model. 
Ambiguity is a challenge because the various readers may perceive different contextual information from requirements specification. Although, there are many solutions provided by different authors to resolve ambiguity in the form of frameworks, models, procedure, techniques, and tools. There are plenty of techniques available for handling different types of SRS ambiguities [5-12]. Although there are many techniques to resolve ambiguity but to date, there is no effective method to handle it. Apart from different frameworks and techniques, there exist a variety of automated tools mentioned by [8] e.g. SREE, QuARS, RESI, ARM, NAI, NL2OCL, and WSD etc. used to detect and resolve ambiguities.

We are planning to work on a technique which can avoid ambiguity so that it shouldn't prevail to SRS document. Finding ambiguity and then removing it is a lengthy and expensive process. We will try to eliminate the ambiguity during elicitation or in the initial phases of SRS development. To avoid ambiguity, we propose framework SRAAF which will select effective elicitation technique and then verify each and every elicited requirement using the $\mathrm{W} 6 \mathrm{H}$ technique. The first task is to select an elicitation technique based on the significant parameters from a large set of elicitation techniques. After choosing the selection technique suggested by the SRAAF, start elicitation process, before finalizing a particular requirement applies W6H technique in a manner to avoid ambiguity. In this paper, we propose a two-phase framework to select the technique based on the available parameters related to project, domain knowledge, stakeholders, elicitor and list of elicitation techniques, which can influence the selection. By using all set of parameters we apply a mapping in the framework to check which technique fits with a particular set of available parameters. After the selection, we will apply W6H to remove a particular type of ambiguity on the elicited requirements. In [13] author provided the set of ordered interrogatives questions for requirement elicitation as $\mathrm{W} 6 \mathrm{H}$ pattern extended from $\mathrm{W} 5 \mathrm{H}$.

- Major categories: thing (what); person (who); place (where); selection (which);

- Minor categories: time (when); manner (how);

- Incidental categories: reason (why);

To process natural language, apart from W6H, domain specific Anaphora resolution [14] can aslo be used that focuses on the problem of resolving what a pronoun, or a noun phrase signifies.

\section{PROBLEM DESCRIPTION}

The process of Requirements Elicitation (RE) is formulating the actual requirements of the customer, to construct a system so that software developers can describe the customer problems in a more systematic way and can focus on their actual requirements. To understand customer requirements in a proper way is still a challenge, as natural language is used as a major tool to communicate with the stakeholders, and they may describe ambiguous and incomplete requirements. As we know requirements are unstable and may change with the passage of time. Selection of RE techniques is influenced by many factors, technical as well as social and greatly affected by many other issues as well. The selection of elicitation technique by requirement engineer is based on the following ideas [15]. That is:

- They use a heuristic approach

- They are comfortable with a particular technique and select it.

- The technique worked good last time, so it will work again in the same manner

- It's the intuition of the requirement engineer that the technique is useful in the present situation.

- The engineer has his own specific methodology for the selection based on it and he recommends a technique.

Many authors study and discovered about the problems related to RE [16-19], and they found that the problem is considerably at higher scales then it seems to be. "Surveys confirmed the project failure rate is much higher, as one-third of the projects started were never completed, and one half of them succeeded only partially". Weaker RE process is the root cause for such failures, more accurately, the lack of stakeholder's interest, unclear objectives, incomplete requirements, ambiguity in requirements, and impractical expectations. Once we are able to select the correct RE technique most of our problems will be solved. As the solution to effective RE is not possible purely through technological way because there are several factors which can affect the selection other than the technical one [20]. Different stakeholders are involved in the process of RE with different level of knowledge, understanding, and experience, to bring all of them together on a common platform and elicit unambiguous requirement is a tedious task.

\section{LITERATURE SURVEY}

In the recent decades, the research field of requirements has broadened. The selection of appropriate $\mathrm{RE}$ technique for a particular domain is crucial. Need to support requirement engineer, to take decision for the effective selection of elicitation tools, and techniques to elicit requirements from the stakeholders. 
In [21] author explains the relationship between the end user requirement and accuracy of Project Management Software. Numerous research papers elaborated various elicitation techniques and prepared guidelines on how to use them [20, 22-24]. A framework is proposed by Maiden et al. [16, 25] to describes the RE selection method. A model proposed by Hickey et al.[17, 19], that focus on the selection of elicitation technique and to elaborates the RE process. Bickerton et al. [19] suggested a model based on the social assumptions, to classify the elicitation techniques. Macaulay [26] proposed a list of the selection of elicitation techniques. Kotonya et al. [27] claim there are attributes that can be useful for the effective selection of the elicitation technique.

S. Lauesen, [28] discussed various techniques that can be applied for elicitation and elaborated that the issues of RE are not tackled appropriately. Extensive research can be performed in the direction, by developing an appropriate methodology for the selection of effective elicitation technique. Whereas Viviane et al., [29] proposed a combined approach, to elicit requirements more effectively. The process of elicitation is based on knowledge model, build around scenarios and stories about the required system and a supporting tool for interaction. For the efficient selection of elicitation technique, Yan Tang et al., [30] proposed a framework based on Bayesian Belief Network to provide the guidance to the stakeholders but didn't focus on many important parameters. We can see that Sumaria et al., [31] presented a method to select elicitation technique, on the basis of parameters and priorities of the project. Zhying [32] worked on a technique, which provides a practical guideline for selection of elicitation technique based on the context of different projects. There are few empirical surveys on the comparison of elicitation techniques. The lack of experiments and experimental environment, techniques, and variables studied by them, make it tough to reach the application environment for elicitation technique [19].

Lauesen's [28] proposal missed three important criteria: basic and fundamental information is based only on the authors' judgment; contextual factors considered only stakeholders and problem domain attributes; and workable supporting tool, as he wasn't able to deliver any provisional tool or software. The proposal by Davis and Hickey's [33] failed on the following four criteria: basic theoretical information; unclear values of attributes; improper subjective fitness or adequacy check; and non-availability of a practical tool to support his model. Proposals described by different authors in [16, 34-36] were unsuccessful on similar criteria as defined above.

In our framework, we will use a selection of effective elicitation technique along with W6H technique to avoid ambiguity. There are seven basic types of interrogatives words in the English Language: which, where, who, why, when, and how [37]. Author extended the W5H set with which to make it W6H. An interrogative word is a function word used to "generate" an interrogative sentence (question). For example, the interrogative sentence 'when will you reach the destination?' is created using interrogative when. In [13] author developed a technique, on the basis of semantic and lexical rules of English Language, to frame interrogative questions for effective requirements elicitation. For better requirement elicitation, he suggested and outlined how to systematize stakeholder viewpoint.

\section{THE PROPOSED FRAMEWORK (SRAAF)}

Requirement Elicitation is a tedious process and can lead to ambiguous requirements. The proposed SRAAF deals with requirement elicitation involved majorly two phases, the first selection of appropriate elicitation technique for effective elicitation based on situational attributes and second applying the W6H technique to handle ambiguity, the detail about the technique is explained in the framework. Implementation of different phases of the framework is as shown in Figure 1.

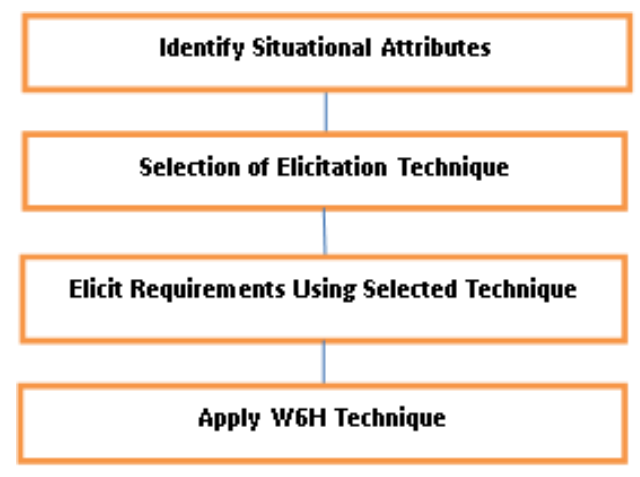

Figure 1. Basic structure of the SRAAF 
- Identify Situational Attributes: Detection of the values linked with the attributes or features of the project, requirement engineer, and associated stakeholders

- Selection of Effective Elicitation Technique: Based on the suitability, set priority for different elicitation (one or more) techniques which can be applied to elicit requirements.

- Requirement Elicitation: Prepare and start eliciting the requirements using open or closed Interviews or Questionnaires.

Apply W6H Technique: ask a question in a sequence as defined in $\mathrm{W} 6 \mathrm{H}$ technique to avoid ambiguity and to get documented unambiguous requirements.

\section{FRAMEWORK DETAILS}

The purpose of the framework is to avoid ambiguity in SRS while requirements elicitation. Figure 2 shows the detailed steps of the framework. As we know there are two phases, the first phase of the framework is how to select an effective requirement elicitation (RE) technique for a particular situation. To proceed, we need detailed information about significant parameters along with elicitation techniques which are in practice and used by academic and industrial partners. Selection of effective RE depends upon various parameters and can be performed in a variety of situations, which may include many aspects like project details (Size, Complexity, and Time etc.), Requirement Engineer(Experience, Training, Domain Knowledge etc.) and stakeholders or participants.

Based on the mapping of situational parameters with significant parameters, we will choose one of the elicitation techniques. Once the effective RE technique is selected according to the situation, we can progress to the next phase, which is how to apply $\mathrm{W} 6 \mathrm{H}$ technique to avoid ambiguity. The detail of each and every step is as follows:

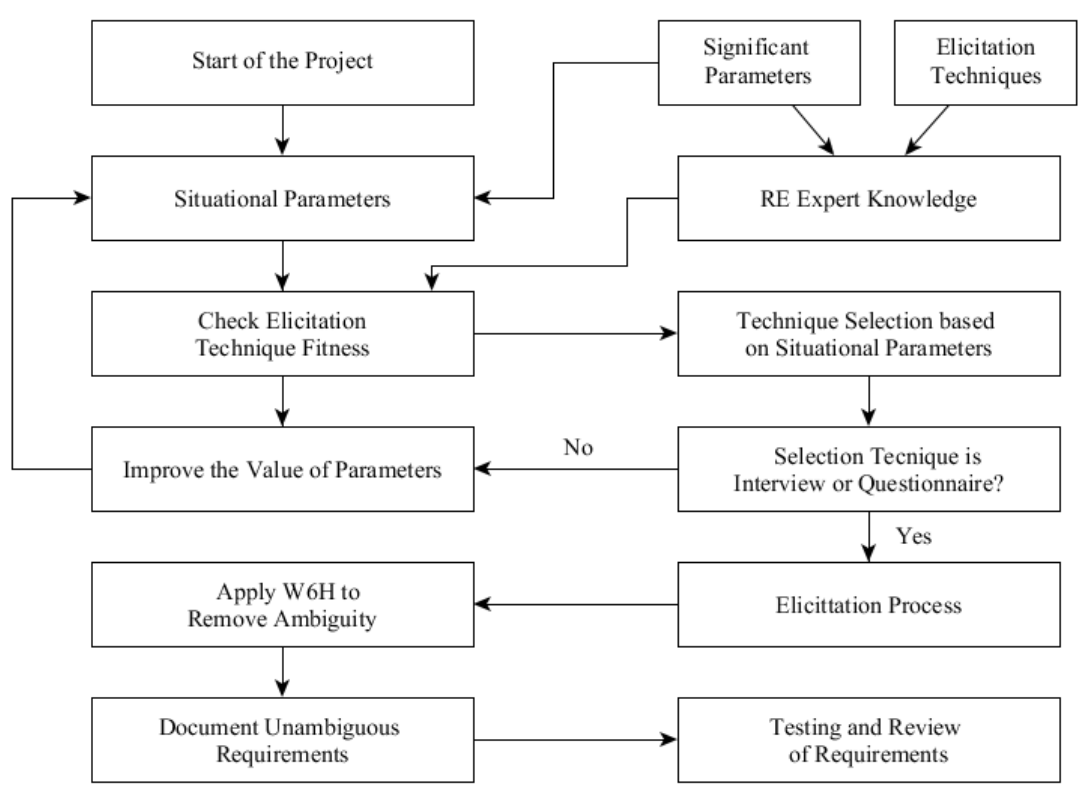

Figure 2. Proposed framework to avoid ambiguity

\subsection{RE expert knowledge}

To create an RE Expert knowledge we searched different databases to identify relevant literature. We initiated a search using a query on IEEE, ACM, Springer, Scopus, Science Direct and books. We made a comparison to check whether our findings include publications from these peer-reviewed papers. We scanned all sources resulting from this selection process. We applied inclusion and exclusion criterion, based on the title and abstract, to select appropriate literature. If we are not able to take a decision based on the title and abstract then further we go into the detail. In order to select elicitation techniques, several papers [20, 22, 23] described various elicitation techniques and their use. There are empirical studies comparing elicitation techniques. RE Expert knowledge consists of two different set of values, list of elicitation techniques and list of significant parameters? It uses the list of significant parameters with a predefined set of values. 


\subsubsection{Determining significant parameters}

Before we select the most suitable elicitation technique, it is important to determine the significant parameters that can affect technique selection. In [38] D. Carrizo et al. listed preliminary set of 34 significant attributes and used only a few in his selection process. Author aggregated and eliminated most of them, but in our framework, we are using 19 important parameters. We clustered the recognized parameters along with possible values into three classes named as Project as shown in Table 1, Requirement Engineer/ Requirement Analyst as shown in Table 2 and Stakeholders as shown in Table 3. Quantity and nature of available information in the form of parameters may affect the selection process and can lead to new selection technique.

Table 1. Project parameters along with possible values

\begin{tabular}{|c|c|c|c|c|c|c|c|}
\hline Size & Complexity & $\begin{array}{l}\text { Requirement } \\
\text { Uncertainty }\end{array}$ & $\begin{array}{c}\text { Time } \\
\text { Constraint }\end{array}$ & $\begin{array}{c}\text { Attainable } \\
\text { Information }\end{array}$ & $\begin{array}{l}\text { Project } \\
\text { Type }\end{array}$ & $\begin{array}{l}\text { Process } \\
\text { Time }\end{array}$ & $\begin{array}{c}\text { Type of } \\
\text { information }\end{array}$ \\
\hline $\begin{array}{l}\text { Small } \\
\text { Medium } \\
\text { Large }\end{array}$ & $\begin{array}{l}\text { Low } \\
\text { Medium } \\
\text { High }\end{array}$ & $\begin{array}{c}\text { Low } \\
\text { Medium } \\
\text { High }\end{array}$ & $\begin{array}{l}\text { Low } \\
\text { Medium } \\
\text { High }\end{array}$ & $\begin{array}{c}\text { Nil } \\
\text { Lesser } \\
\text { Higher }\end{array}$ & $\begin{array}{c}\text { New } \\
\text { Existing }\end{array}$ & $\begin{array}{c}\text { Beginning } \\
\text { Intermediate } \\
\text { Final-Stage }\end{array}$ & $\begin{array}{c}\text { Elementary } \\
\text { Important } \\
\text { Critical }\end{array}$ \\
\hline
\end{tabular}

Table 2. Requirement engineer/requirement analyst along with possible values

\begin{tabular}{ccccc}
\hline $\begin{array}{c}\text { Experience with } \\
\text { elicitation technique }\end{array}$ & Formal & Elicitation & Domain & Problem \\
Training & Experience & Experience & Understanding \\
\hline Zero & Low & Novice & Novice & Partial, \\
Low & Medium & Experience & Experience & Complete \\
High & High & Proficient & Proficient & \\
\hline
\end{tabular}

Table 3. Stakeholders along with possible values

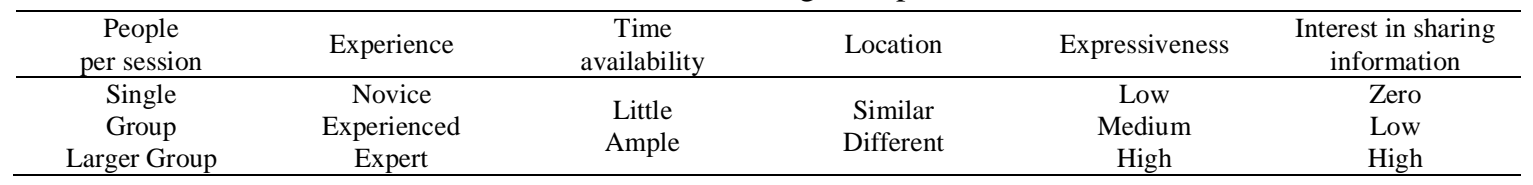

\subsubsection{List of elicitation techniques}

A "technique" is a way of performing or applying the practical method to complete some useful tasks [36]. On the other hand, an "Approach" is an organized arrangement, in the form of ideas, steps, or actions performed to deal with a situation or problem. There are plenty of RE techniques described by authors. Most of the time, we look for a simple and easy RE technique to elicit requirements. We can't apply the same RE techniques as the situational parameters may vary for different projects in the real-life situation. There are many approaches and techniques that can be applied to elicit requirements. All these techniques can be arranged into majorly four groups, Traditional, Group-Based, Scenario-Based, and Contextual.

Requirement Engineers apply different RE technique to elicit requirements, according to the project domain and there comfort level. Here we will focus on the techniques shown in Figure 3. As for the rest of the techniques, we won't be able to collect the values for the significant parameters, which we will use in the selection process of elicitation technique.

\subsection{Situational parameters}

Here, we will identify the situational parameters of the project under consideration. The current status and settings of the project will define the situational parameters or contextual parameters. In this step, we will check the values of all significant parameters for the current project and will register required in a tabular format so that we can map these values with our RE Expert Knowledge as shown in Table 4 (a, b, c) to select the appropriate RE technique.

\subsection{Check the suitability of the technique}

This is one of the important steps, as we are going to select the effective elicitation technique based on the situational parameters. To check the suitability we will use the situational parameters and map it with significant parameters in Table 4(a, b, c). To verify the result we need the significant parameter values for each and every technique. To get the data for all techniques we searched many sources and generated a two dimensional matrix. This matrix contains significant parameters value all RE techniques under consideration. 
We populated the values of parameters for all techniques in the table, from various sources. Using the existing information, expert knowledge, and RE knowledge base we identify the relevant information for mapping.

Table 4(a). Adequacy values of the significant attributes for different elicitation technique (project)

\begin{tabular}{|c|c|c|c|c|c|c|c|c|}
\hline & \multicolumn{8}{|c|}{ Project } \\
\hline Attributes & Size & Complexity & $\begin{array}{l}\text { Requirement } \\
\text { Uncertainty }\end{array}$ & $\begin{array}{c}\text { Time } \\
\text { constraint }\end{array}$ & $\begin{array}{c}\text { Attainable } \\
\text { Information }\end{array}$ & $\begin{array}{c}\text { Project } \\
\text { Type }\end{array}$ & $\begin{array}{c}\text { Process } \\
\text { Time }\end{array}$ & $\begin{array}{c}\text { Type of } \\
\text { Information }\end{array}$ \\
\hline Values & $\begin{array}{c}\text { Small } \\
\text { Medium } \\
\text { Large }\end{array}$ & $\begin{array}{c}\text { Low } \\
\text { Medium } \\
\text { High }\end{array}$ & $\begin{array}{c}\text { Low } \\
\text { Medium } \\
\text { High }\end{array}$ & $\begin{array}{c}\text { Low } \\
\text { Medium } \\
\text { High }\end{array}$ & $\begin{array}{c}\text { Nil } \\
\text { Lesser } \\
\text { Higher }\end{array}$ & $\begin{array}{c}\text { New } \\
\text { Existin } \\
\mathrm{g}\end{array}$ & $\begin{array}{c}\text { Beginning } \\
\text { Intermediate } \\
\text { Final-Stage }\end{array}$ & $\begin{array}{c}\text { Elementary } \\
\text { Important } \\
\text { Critical }\end{array}$ \\
\hline Questionnaires & $\mathrm{M}$ & $\mathrm{H}$ & $\mathrm{L}, \mathrm{M}$ & $\mathrm{L}, \mathrm{M}, \mathrm{H}$ & $\mathrm{L}, \mathrm{H}$ & $\mathrm{N}, \mathrm{E}$ & I, F & E, I, C \\
\hline $\begin{array}{l}\text { Open-ended } \\
\text { Interview }\end{array}$ & $\mathrm{S}, \mathrm{M}, \mathrm{L}$ & $\mathrm{M}, \mathrm{H}$ & $\mathrm{M}, \mathrm{H}$ & $\mathrm{L}, \mathrm{M}$ & $\mathrm{N}, \mathrm{L}, \mathrm{H}$ & $\mathrm{N}, \mathrm{E}$ & $\mathrm{B}, \mathrm{I}, \mathrm{F}$ & I, C \\
\hline $\begin{array}{l}\text { Structured } \\
\text { interview }\end{array}$ & M, L & $\mathrm{L}, \mathrm{M}$ & $\mathrm{L}, \mathrm{M}$ & $\mathrm{L}, \mathrm{M}$ & $\mathrm{L}, \mathrm{H}$ & $\mathrm{E}$ & I, F & E, I \\
\hline $\begin{array}{l}\text { Brain- } \\
\text { Storming }\end{array}$ & M, L & $\mathrm{M}, \mathrm{H}$ & $\mathrm{L}, \mathrm{M}$ & $\mathrm{L}$ & $\mathrm{N}, \mathrm{L}$ & $\mathrm{N}$ & B & I, C \\
\hline $\begin{array}{l}\text { Task } \\
\text { Observation }\end{array}$ & $\mathrm{S}, \mathrm{M}$ & $\mathrm{H}$ & $\mathrm{L}$ & $\mathrm{L}$ & $\mathrm{N}, \mathrm{L}, \mathrm{H}$ & $\mathrm{E}$ & B & I \\
\hline $\begin{array}{l}\text { Document } \\
\text { Analysis }\end{array}$ & M, L & $\mathrm{M}, \mathrm{H}$ & M & M, H & $\mathrm{N}, \mathrm{L}, \mathrm{H}$ & $\mathrm{E}$ & B, I & E, I \\
\hline $\begin{array}{l}\text { Protocol } \\
\text { Analysis }\end{array}$ & M & M & $\mathrm{M}, \mathrm{H}$ & $\mathrm{L}$ & $\mathrm{H}$ & $\mathrm{N}, \mathrm{E}$ & I & I \\
\hline $\begin{array}{l}\text { Participant } \\
\text { Observation }\end{array}$ & S, M, L & $\mathrm{H}$ & $\mathrm{L}$ & $\mathrm{L}$ & $\mathrm{N}, \mathrm{L}, \mathrm{H}$ & $\mathrm{E}$ & B, I & I, C \\
\hline $\begin{array}{l}\text { Repertory } \\
\text { Grid }\end{array}$ & $\mathrm{S}$ & $\mathrm{L}, \mathrm{M}$ & $\mathrm{L}, \mathrm{M}$ & $\mathrm{L}, \mathrm{M}, \mathrm{H}$ & $\mathrm{L}$ & $\mathrm{N}, \mathrm{E}$ & I & $\mathrm{E}$ \\
\hline $\begin{array}{l}\text { Nominal } \\
\text { Group }\end{array}$ & M, L & $\mathrm{L}, \mathrm{M}$ & $\mathrm{L}, \mathrm{M}$ & $\mathrm{L}$ & $\mathrm{H}$ & E & B, I & I, C \\
\hline $\begin{array}{l}\text { Delphi } \\
\text { Technique }\end{array}$ & S, M, L & $\mathrm{M}, \mathrm{H}$ & $\mathrm{L}, \mathrm{M}$ & $\mathrm{L}$ & $\mathrm{L}, \mathrm{H}$ & $\mathrm{E}$ & I & I, C \\
\hline $\begin{array}{l}\text { Scenarios/ } \\
\text { Use cases }\end{array}$ & S, M, L & $\mathrm{L}, \mathrm{M}, \mathrm{H}$ & $\mathrm{M}, \mathrm{H}$ & $\mathrm{L}, \mathrm{M}$ & $\mathrm{N}, \mathrm{L}, \mathrm{H}$ & $\mathrm{N}, \mathrm{E}$ & I & I \\
\hline Prototyping & $\mathrm{S}$ & $\mathrm{H}$ & $\mathrm{H}$ & $\mathrm{L}$ & $\mathrm{L}, \mathrm{H}$ & $\mathrm{N}$ & I & E, I \\
\hline Focus Group & $\mathrm{S}, \mathrm{M}, \mathrm{L}$ & $\mathrm{H}$ & $\mathrm{L}$ & $\mathrm{L}$ & $\mathrm{H}$ & $\mathrm{N}, \mathrm{E}$ & B.I & I, C \\
\hline $\begin{array}{l}\text { JAD/RAD } \\
\text { workshop }\end{array}$ & M, L & M & $\mathrm{H}$ & $\mathrm{L}$ & $\mathrm{N}, \mathrm{L}, \mathrm{H}$ & $\mathrm{N}$ & B & I, C \\
\hline $\begin{array}{l}\text { Card } \\
\text { Sorting/Ladd }\end{array}$ & M & $\mathrm{H}$ & M & $\mathrm{L}, \mathrm{M}, \mathrm{H}$ & $\mathrm{L}$ & E & B, I & $\mathrm{E}$ \\
\hline
\end{tabular}

Table 4(b). Adequacy values of the significant attributes for different elicitation technique (requirement engineer)

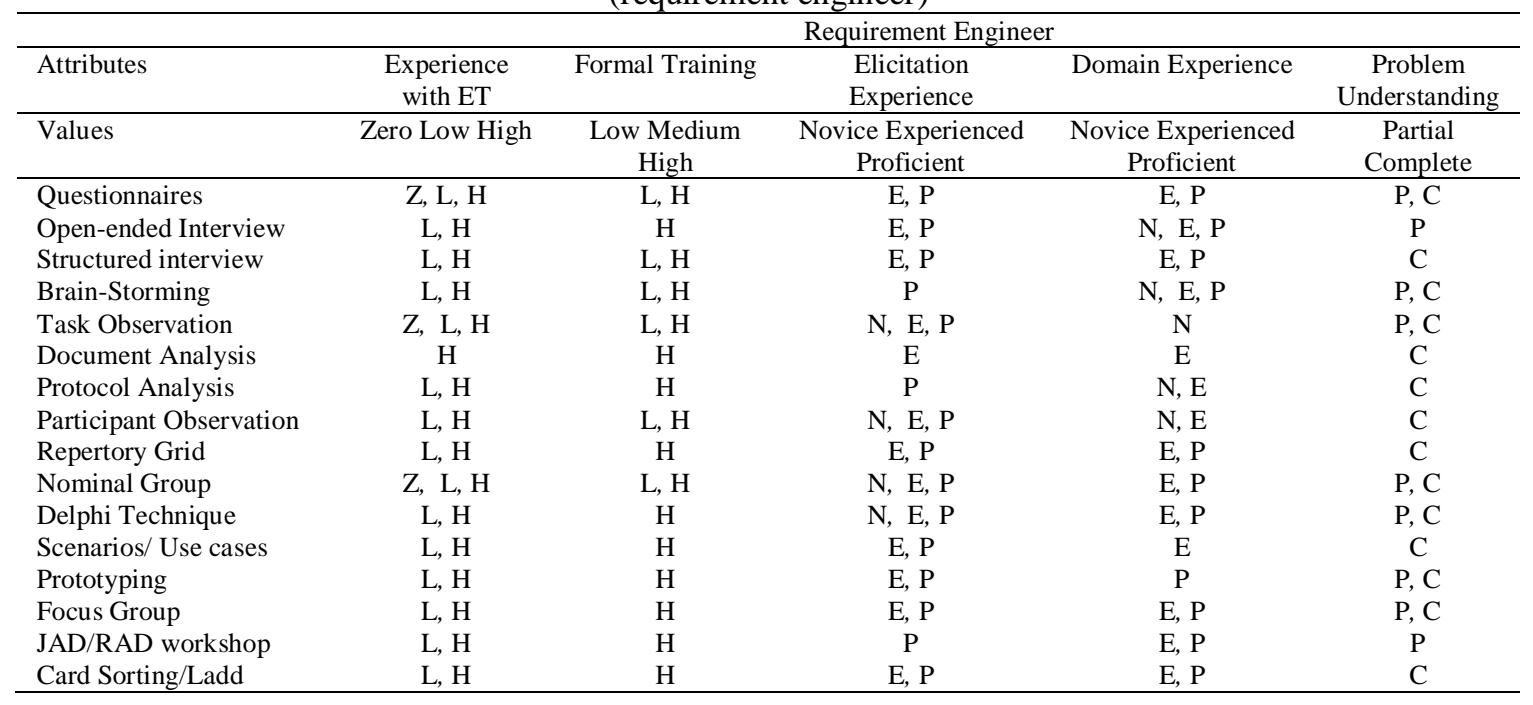


Table 4(c). Adequacy values of the significant attributes for different elicitation technique (stakeholder)

\begin{tabular}{|c|c|c|c|c|c|c|}
\hline \multirow[b]{2}{*}{ Attributes } & \multicolumn{6}{|c|}{ Stakeholder } \\
\hline & $\begin{array}{l}\text { People per } \\
\text { Section }\end{array}$ & Experience & $\begin{array}{c}\text { Time } \\
\text { Availability }\end{array}$ & Location & Expressiveness & Participation \\
\hline Values & $\begin{array}{c}\text { Single Group } \\
\text { Large G }\end{array}$ & $\begin{array}{l}\text { Novice Experienced } \\
\text { Proficient }\end{array}$ & $\begin{array}{c}\text { Little } \\
\text { Ample }\end{array}$ & $\begin{array}{c}\text { Similar } \\
\text { Different }\end{array}$ & $\begin{array}{c}\text { Low Medium } \\
\text { High }\end{array}$ & $\begin{array}{c}\text { Low Zero } \\
\text { High }\end{array}$ \\
\hline Questionnaires & $\mathrm{S}, \mathrm{G}, \mathrm{L}$ & $\mathrm{N}, \mathrm{E}, \mathrm{P}$ & $\mathrm{L}, \mathrm{A}$ & S,D & $\mathrm{L}, \mathrm{M}, \mathrm{H}$ & Z,L,H \\
\hline Open-ended Interview & $\mathrm{S}$ & E,P & A & $S$ & M,H & $\mathrm{H}$ \\
\hline Structured interview & $\mathrm{S}$ & E,P & A & S & M,H & $\mathrm{H}$ \\
\hline Brain-Storming & $\mathrm{L}$ & N,E,P & A & S & $\mathrm{L}, \mathrm{M}, \mathrm{H}$ & $\mathrm{H}$ \\
\hline Task Observation & $\mathrm{S}, \mathrm{G}$ & $\mathrm{N}, \mathrm{E}$ & $\mathrm{L}, \mathrm{A}$ & $\mathrm{S}$ & $\mathrm{L}, \mathrm{M}, \mathrm{H}$ & $\mathrm{Z}, \mathrm{L}, \mathrm{H}$ \\
\hline Document Analysis & $\mathrm{G}$ & N,E,P & $\mathrm{L}$ & S,D & M,H & $\mathrm{H}$ \\
\hline Protocol Analysis & $\mathrm{S}$ & $\mathrm{P}$ & A & $\mathrm{S}$ & $\mathrm{H}$ & $\mathrm{H}$ \\
\hline Participant Observation & $\mathrm{S}, \mathrm{G}, \mathrm{L}$ & N,E,P & A & $\mathrm{S}$ & M,H & $\mathrm{H}$ \\
\hline Repertory Grid & $\mathrm{S}, \mathrm{G}, \mathrm{L}$ & N,E,P & $\mathrm{L}, \mathrm{A}$ & S,D & $\mathrm{L}, \mathrm{M}, \mathrm{H}$ & $\mathrm{Z}, \mathrm{L}, \mathrm{H}$ \\
\hline Nominal Group & $\mathrm{G}, \mathrm{L}$ & N,E,P & A & S & M,H & $\mathrm{Z}, \mathrm{L}, \mathrm{H}$ \\
\hline Delphi Technique & $\mathrm{G}, \mathrm{L}$ & $\mathrm{P}$ & $\mathrm{L}, \mathrm{A}$ & S,D & $\mathrm{L}, \mathrm{M}, \mathrm{H}$ & $\mathrm{Z}, \mathrm{L}, \mathrm{H}$ \\
\hline Scenarios/ Use cases & $\mathrm{S}$ & N,E,P & A & $\mathrm{S}$ & M,H & $\mathrm{L}, \mathrm{H}$ \\
\hline Prototyping & $\mathrm{S}$ & N,E,P & A & S & $\mathrm{L}, \mathrm{M}, \mathrm{H}$ & $\mathrm{Z}, \mathrm{L}, \mathrm{H}$ \\
\hline Focus Group & G,L & N,E,P & A & $S$ & M,H & $\mathrm{L}, \mathrm{H}$ \\
\hline JAD/RAD workshop & $\mathrm{L}$ & N,E,P & A & S & M,H & $\mathrm{H}$ \\
\hline Card Sorting/Ladd & $\mathrm{S}$ & N,E,P & A & $\mathrm{S}$ & $\mathrm{L}, \mathrm{M}, \mathrm{H}$ & $\mathrm{L}, \mathrm{H}$ \\
\hline
\end{tabular}

\subsection{Selection of appropriate technique}

We have all necessary information in line, to select an appropriate RE technique for explicit elicitation sessions. Our selection process is based on the adequacy table in which we populated information of various parameters for different elicitation techniques. As we know, it's a significant extraction of the information, but still, there can be deficiencies. How to combine this adequacy table information to select the effective technique is solely depend upon requirement engineer's decision. A complete and final solution should select more than one technique according to the fitness of the techniques. Now by judging conditions and based on the situation, requirements engineer will be able to take a decision, that which technique can be applied to a particular elicitation session.

\subsection{Selection of different elicitation technique (by improving parameters)}

The selection process offers a list of adequate or less adequate techniques. When there are no adequate techniques, or we wanted to select a different technique we can improve the values of situational parameters. Here we are using 19 different situational parameters, most of them are either fixed (Project Size and Complexity, etc.) or rigid, and there are only few which are flexible (Experience with elicitation technique, Elicitation Experience, Domain Experience, Time Availability, Location, People Per session, etc.). To choose a different technique we can always improve the flexible situational parameter.

\subsection{Elicitation process}

The process of Requirements elicitation is uncovering, seeking, obtaining, and elaborating requirements for a system. It is a process, in which we elicit and understating the meaning of requirements instead of just captures or gather a requirement. RE can be performed using many tools, techniques, and approaches and it involves plenty of activities. So we won't go into the detail of the elicitation process rather we will follow the process defined by various authors and academicians for the technique selected by our framework. Our focus is on the selection of the technique and applying $\mathrm{W} 6 \mathrm{H}$ on elicited requirements to handle the issue of Ambiguity.

\subsection{Applying $\mathrm{W6H}$ on requirements}

In [13] author explained, how $\mathrm{W} 6 \mathrm{H}$ pattern is used to formulate questions to be asked by requirement engineer or analyst to the stakeholders. He also explained the order of the interrogative question, in which order they must be asked for effective RE. Both requirements elicitation and gap bridging are widespread challenging tasks. Using W6H pattern structured approach we can tackle these issues. As Cysouw [39] describes the interrogative categories:

- Major classes: who (person), what (thing), which (selection), where (place);

- Minor classes: how (manner), when (time);

- Incidental classes: why (reason).

Here we will use the same approach but in a different way to remove ambiguity from the elicited requirements. We will apply the interrogative question to all statements in the same order. 
Example 1: John dropped the cup onto the glass table, it broke. This statement is ambiguous as we don't know glass is broken or table.

As glass and table, both are a noun, the relevant question is what broke? In this statement its' not clear what broke? Glass or table?

The benefit of the $\mathrm{W} 6 \mathrm{H}$ is it will remove the ambiguity and can complete the required information. As in this case, he may ask when the table or glass is broken, along with why he broke.

\begin{tabular}{ll}
\hline What & Relevant \\
When & Irrelevant \\
Where & Irrelevant \\
Which & Irrelevant \\
Who & Irrelevant \\
Why & Irrelevant \\
How & Irrelevant \\
\hline
\end{tabular}

\subsection{Documenting and reviewing requirements}

The required documentation is concerned with the controlling and organizing a large number of requirements elicited for a particular project. After applying the $\mathrm{W} 6 \mathrm{H}$ technique, requirements engineers are liable for documenting \& reviewing the requirements elicited. The role of documentation is especially important as it signifies the final step of the requirement elicitation using the framework and of great importance for successful execution of next phases of the project. Review of the elicited requirement and the work completed by the analyst or Requirement Engineer is based on the output produces in the previous step of documentation. As we know, software projects have fixed budget and time constraint, therefore documented requirements should come as approved document based on the user's real need [22].

\section{CONCLUSION}

Ambiguous statements written in the Natural language is very common and gained the focus of researchers, linguists, and academicians. Most of the previous work to handle ambiguity in SRS has focused only on detecting and then removing it. Despite so many tools and techniques, the problem of ambiguity is still a challenging issue. But our focus is on how to avoid ambiguities before we write any statement to the SRS. There are two major issues encountered by every Requirements engineer: choosing the effective RE technique and how to control ambiguity. The SRAAF can handle both issues effectively and can be applied to small and medium scale projects. Our future work will provide the basis to automate the effective selection of RE method described in this paper. As we know the full automation would involve advanced natural language processing (NLP) technologies that can apply W6H technique, which is not currently available.

\section{REFERENCES}

[1] A. Bucchiarone, et al., "Quality analysis of NL requirements: an industrial case study," 13th IEEE International Conference on Requirements Engineering (RE'05), pp. 390-394, 2005.

[2] J. Scheffczyk, et al., "Pragmatic consistency management in industrial requirements specifications," Software Engineering and Formal Methods, 2005. SEFM 2005. Third IEEE International Conference on, pp. 272-281, 2005.

[3] F. Belfo, "People, organizational and technological dimensions of software requirements specification," Procedia Technology, vol. 5, pp. 310-318, 2012.

[4] T. Wahyuningrum and K. Mustofa, "A Systematic Mapping Review of Software Quality Measurement: Research Trends, Model, and Method," International Journal of Electrical and Computer Engineering (IJECE), vol. 7, 2017.

[5] J. Polpinij, "An ontology-based text processing approach for simplifying ambiguity of requirement specifications," Services Computing Conference, 2009. APSCC 2009. IEEE Asia-Pacific, pp. 219-226, 2009.

[6] M. Bhatia, et al., "Ontology based framework for detecting ambiguities in software requirements specification," Computing for Sustainable Global Development (INDIACom), 2016 3rd International Conference on, pp. 3572-3575, 2016.

[7] A. Rashwan, et al., "Ontology-based classification of non-functional requirements in software specifications: a new corpus and svm-based classifier," Computer Software and Applications Conference (COMPSAC), 2013 IEEE 37th Annual, pp. 381-386, 2013.

[8] U. S. Shah and D. C. Jinwala, "Resolving ambiguities in natural language software requirements: a comprehensive survey," ACM SIGSOFT Software Engineering Notes, vol. 40, pp. 1-7, 2015.

[9] E. Kabaale and G. M. Kituyi, "A theoretical framework for requirements engineering and process improvement in small and medium software companies," Business Process Management Journal, vol. 21, pp. 80-99, 2015.

[10] C. Arora, et al., "Automated checking of conformance to requirements templates using natural language processing," IEEE transactions on Software Engineering, vol. 41, pp. 944-968, 2015. 
[11] C. Arora, et al., "Requirement boilerplates: Transition from manually-enforced to automatically-verifiable natural language patterns," Requirements Patterns (RePa), 2014 IEEE 4th International Workshop on, pp. 1-8, 2014.

[12] S. F. Tjong and D. M. Berry, "The design of SREE - a prototype potential ambiguity finder for requirements specifications and lessons learned," International Working Conference on Requirements Engineering: Foundation for Software Quality, pp. 80-95, 2013.

[13] M. Sultan and A. Miranskyy, "Ordering interrogative questions for effective requirements engineering: The W6H pattern," Requirements Patterns (RePa), 2015 IEEE Fifth International Workshop on, pp. 1-8, 2015.

[14] R. Sonbol, et al., "Anaphora Resolution in Business Process Requirement Engineering," International Journal of Electrical and Computer Engineering (IJECE), vol. 8, 2018.

[15] A. M. Hickey and A. M. Davis, "Elicitation technique selection: how do experts do it?" Proceedings. 11th IEEE International Requirements Engineering Conference, pp. 169-178, 2003.

[16] N. A. Maiden and G. Rugg, "ACRE: selecting methods for requirements acquisition," Software Engineering Journal, vol. 11, pp. 183-192, 1996.

[17] A. M. Hickey and A. M. Davis, "Requirements elicitation and elicitation technique selection: model for two knowledge-intensive software development processes," System Sciences, 2003. Proceedings of the 36th Annual Hawaii International Conference on, pp. 10, 2003.

[18] A. M. Hickey and A. M. Davis, "Elicitation technique selection: how do experts do it?, " Requirements engineering conference, 2003. proceedings. 11th ieee international, pp. 169-178, 2003.

[19] M. J. Bickerton and J. Siddiqi, "The classification of requirements engineering methods," Requirements Engineering, Proceedings of IEEE International Symposium on, pp. 182-186, 1993.

[20] J. A. Goguen and C. Linde, “Techniques for requirements elicitation, ” Requirements Engineering, Proceedings of IEEE International Symposium on, pp. 152-164, 1993.

[21] F. Fachrurrazi, "The End User Requirement for Project Management Software Accuracy," International Journal of Electrical and Computer Engineering (IJECE), vol. 8, pp. 1112, 2018.

[22] G. Playle and C. Schroeder, "Software requirements elicitation: Problems, tools, and techniques," Crosstalk: The Journal of Defense Software Engineering, vol. 9, pp. 19-24, 1996.

[23] H. Saiedian and R. Dale, "Requirements engineering: making the connection between the software developer and customer," Information and Software Technology, vol. 42, pp. 419-428, 2000.

[24] B. Nuseibeh and S. Easterbrook, "Requirements Engineering: A Roadmap, The Future of Software Engineering," Anthony Finkelstein, ed: ACM Press, 2000.

[25] G. J. Browne and V. Ramesh, "Improving information requirements determination: a cognitive perspective," Information \& Management, vol. 39, pp. 625-645, 2002.

[26] L. Macaulay, "Requirements for requirements engineering techniques, " Requirements Engineering, Proceedings of the Second International Conference on, pp. 157-164, 1996.

[27] G. Kotonya and I. Sommerville, "Requirements engineering: processes and techniques," Wiley Publishing, 1998.

[28] S. Lauesen, "Software requirements: styles and techniques," Pearson Education, 2002.

[29] V. Laporti, et al., "A collaborative approach to requirements elicitation," Computer Supported Cooperative Work in Design, CSCWD 2007. 11th International Conference on, ,pp. 734-739, 2007.

[30] Y. Tang, et al., "Requirement engineering techniques selection and modeling an expert system based approach," Machine Learning and Applications, 2009. ICMLA'09. International Conference on, pp. 705-709, 2009.

[31] S. Kausar, et al., "Guidelines for the selection of elicitation techniques, ” Emerging Technologies (ICET), 2010 6th International Conference on, pp. 265-269, 2010.

[32] Z. Zhang, "Effective requirements development-A comparison of requirements elicitation techniques," Software Quality Management XV: Software Quality in the Knowledge Society, E. Berki, J. Nummenmaa, I. Sunley, M. Ross and G. Staples (Ed.) British Computer Society, pp. 225-240, 2007.

[33] A. Hickey and A. Davis, "A tale of two ontologies: The basis for systems analysis technique selection," AMCIS 2003 Proceedings, pp. 386, 2003.

[34] J. S. Dhaliwal and I. Benbasat, "A framework for the comparative evaluation of knowledge acquisition tools and techniques,” Knowledge Acquisition, vol. 2, pp. 145-166, 1990.

[35] S. Robertson and J. Robertson, Mastering the requirements process: Getting requirements right, Addison-wesley, 2012.

[36] D. Zowghi and C. Coulin, “Requirements elicitation: A survey of techniques, approaches, and tools, " Engineering and managing software requirements, ed: Springer, pp. 19-46, 2005.

[37] M. Cysouw, "Interrogative words: an exercise in lexical typology," Presentation presented at the Bantu grammar: description and theory workshop, 2004.

[38] D. Carrizo, et al., "Systematizing requirements elicitation technique selection," Information and Software Technology, vol. 56, pp. 644-669, 2014.

[39] M. Cysouw, "The typology of content interrogatives," Talk presented at the 6th meeting of the Association for Linguistic Typology. Padang, Indonesia, 2005. 


\section{BIOGRAPHIES OF AUTHORS}
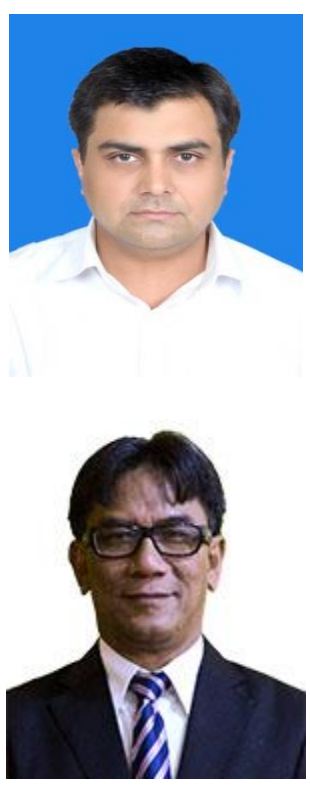

Ashok Kumar Gupta, Lecturer, Department of Computer Science, College of Computer Science \& Innformation Technology, Jazan University, Jazan, KSA Research Scholar, Universiti of Malaysia Terengganu, Kuala Terengganu, Malaysia M-Tech (Punjabi University Patiala).

Prof. Dato' Dr. Aziz Deraman, Dean, School of Informatics and Applied Mathematics, Universiti of Malaysia Terengganu, Kuala Terengganu, Malaysia, PhD (UMIST, 1992). 